
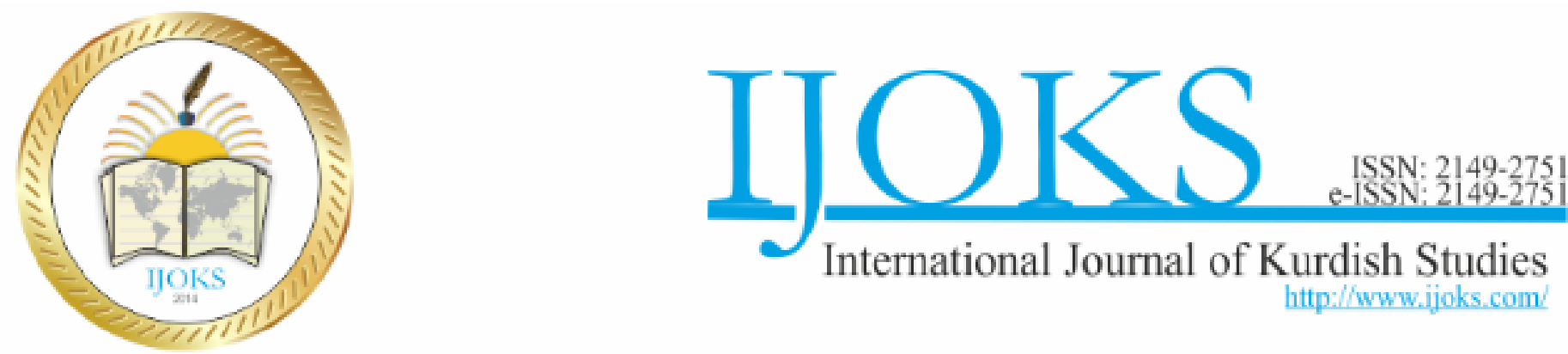

Article

International Journal of Kurdish Studies

7 (2), pp. 206-227

http://ijoks.com

\title{
Hewldaneke Tasnîfa Efsaneyên Kurdan Li Gorî Rêbaza Juha Pentikainen: Mînaka Herêma Semsurê
}

\author{
Tekin ÇIFÇİ $\dot{I}^{1}$
}

Received: May 11, $2021 \quad$ Reviewed: May 29, $2021 \quad$ Accepted: June 21, 2021

\section{Kurte}

Yek ji cureyên vegotinên gelêrî efsane ne ku di jiyana rojane a gel de cihekî girîng digrin. Efsane, beriya hezar salan heta niha "wekî çîrok û serhatiyên rastî" yên civakê di mijarên afirandin û xerabûna dînyayê (roja qiyametê), rûdanên dîrokî yên şaristaniyan, rûdan û heyînên derasayî û kesên olî/lehengî û hwd. de bi awayekî devkî hatine vegotin û gihaştine roja îro. Ji bo nasîn û fềmkirina bawerî û bîra civakî ya gel tasnîfkirina efsaneyan gelekî girîng e. Bi taybetî ji bo parastina çand û edebiyata devkî ya kurdan tomarkirin, tasnîf û nirxandinên li ser efsaneyan pêwîsteyeke nebe nabe ye. Di vê çarçoveyê de mebesta vê xebatê, hewldana tasnifkirina efsaneyên kurdan bi rêbaza Juha Pentikainen e ku li herêma bajarê Semsûrê hatine tomarkirin. Di vê xebatê de, bi 21 kesên jêder re bi teknîka gogberfê hevpeyvînên rû bi rû hatiye kirin. Di encama van hevpeyvînan de, 28 efsaneyên ku li herêmê têne gotin hatine tespîtkirin, tomarkirin, deşîfrekirin. Efsane, li gorî tasnîfa Juha Pentikainen hatine tasnîfkirin û kurteya wan hatiye dayîn. Di encamê de hate dîtin ku li herêma Semsûrê 7 heb efsaneyên gerok û 21 jî efsaneyên herêmî têne gotin. Efsaneyên ku di nav gel de têne gotin ji aliyê teşe, cure û motîfan ve xwediyê karaktereke gerdûnî ne. Piraniya efsaneyan ji aliyê mêran ve têne gotin. Lê belê, efsaneyên derbarê kerametên kesên olî de bêtir ji aliyê jinan ve têne vegotin û nirxê dibînin. Herweha hate tespîtkirin ku efsane, ji bilî karakterên xwe yên edebî û hunerî di sazkirin û rêveberina jiyana rojane a gel de roleke girîng dilîzin.

Peyvên Sereke: Efsane, Efsaneyên Kurdan, Semsûr, Tasnîfa Pentikainen, Peywirên Efsaneyan

\section{Recommended citation:}

Çifçi, T. (2021). Hewldaneke Tasnîfa Efsaneyên Kurdan Li Gorî Rêbaza Juha Pentikainen: Mînaka Herêma Semsurê. International Journal of Kurdish Studies 7 (2), 206-227, https://doi.org/10.21600/ijoks.936115

\footnotetext{
${ }^{1}$ PhD., Haci Hamdiye Ozdemir Primary School, Artuklu/Mardin, E-mail: tekincifci02@gmail.com ORCID ID: 0000-0002-1003-1711
} 


\title{
An Attempt to Classify Kurdish Legends Using the Juha Pentikainen Method: Example of Adıyaman
}

\begin{abstract}
Legends are one of the genres of folk narrative that occupy an important place in the daily life of the people. Legends, the creation and destruction of the world for thousands of years; historical events; supernatural beings and events; They are folk narratives that are believed to be "as if they are real" in many subjects, including religious leaders and heroes, and that are transmitted from generation to generation by developing and transforming. The classification of the legends is important in order to know and understand the social memory and beliefs of the people closely. It is urgent to compile, classify and analyze legends, especially in terms of preserving and maintaining Kurdish oral culture and literature. The aim of this article is to determine the Kurdish folk legends compiled from the region of Adiyaman province and to try to classify them with Juha Pentikainen method. In this study, face-to-face interview technique was applied with 21 people who were knowledgeable about the subject and were identified with the snowball method. As a result of the interviews, 28 legends from the region were identified, compiled and deciphered. The legends are classified as traveler and locale, according to the method of Juha Pentikainen, and are summarized. As a result, legends of both types were found in Adiyaman region, 7 travelers and 21 of them local. It has been observed that the legends have a universal character in terms of genre, form and motif. Most of the legends are narrated by men, but it has been determined that the legends about the miracles about personalities important in terms of religious representation are mostly told and cared by women. It has been determined that the legends play an important role in the establishment and execution of the social order as well as their literary and artistic characters.
\end{abstract} Keywords: Legend, Kurdish Legends, Adiyaman, Classification of Pentikainen, Function of legends

\section{Kürt Efsanelerini Juha Pentikainen Metoduyla Tasnif Denemesi: Adıyaman Bölgesi Örneği}

$\ddot{O} z$

Efsaneler, halkın günlük yaşamında önemli bir yer tutan halk anlatısı türlerinden biridir. Efsaneler, binlerce yıldan beri başta dünyanın yaradılışı, yıkılışı ( kıyamet günü); tarihi olaylar; tabiatüstü varlıklar ve olaylar; dini önderler ve kahraman kişiler olmak üzere birçok 
konuda "gerçekmiş gibi" inanılan ve nesilden nesile gelişerek ve dönüşerek aktarılan halk anlatılarıdır. Efsanelerin tasnifi, halkın toplumsal belleğini ve inançlarını yakından tanımak ve anlamak açısından önemlidir. Özellikle Kürt sözlü kültürü ve edebiyatının korunması ve yaşatılması açısından efsanelerin derlenmesi, tasnifi ve incelenmesi elzemdir. Bu makalenin amac1, Adıyaman bölgesinden derlenen Kürt halk efsanelerinin tespiti ve Juha Pentikainen metoduyla tasnif denemesidir. Çalışmada, konu ilgili bilgi sahibi olan ve kartopu yöntemiyle tespit edilen 21 kişi ile yüz yüze görüşme tekniği uygulanmıştır. Görüşmeler neticesinde, bölgede söylenegelen 28 efsane tespit edilmiş, derlenmiş ve deşifre edilmiştir. Efsaneler, Juha Pentikainen'in metoduna göre gezgin ve mahalli olarak tasnif edilmiş ve özet olarak verilmiştir. Sonuç olarak, Adıyaman bölgesinde 7'si gezgin ve 21'i mahalli olmak üzere her iki türde efsanelere rastlanmıştır. Efsanelerin tür, biçim ve motif bakımından evrensel bir karakterde olduğu görülmüştür. Efsanelerin çoğu erkekler tarafından anlatılmaktadır ancak dini temsiliyet bakımından önemli karakterlerle ilgili kerametlere dair efsanelerin daha çok kadınlar tarafından anlatıldığg ve önemsendiği tespit edilmiştir. Efsanelerin edebi ve sanatsal karakterlerinin yanı sıra toplumsal düzenin kurulmasında ve yürütülmesinde önemli bir rol oynadıkları tespit edilmiştir.

Anahtar Kelimeler: Efsane, Kürt Efsaneleri, Adıyaman, Pentikainen Tasnifi, Efsanelerin işlevi

\section{Destpêk}

Efsane, çîrok û vegotinên xeyalî yên derbarê heyber û bûyerên derasayî de ne ku ji hezar salan û vir de digindirin, dihugerin, kêm an zêde dibin lê hebûna xwe her didomînin. Li her devera dinyayê mirov dikare mînakên efsaneyên ku bawerî û çanda hevpar a civakê nîşan didin bibîne. Efsane wekî peyv, ji zimanê farisî derbasî kurdî û tirkî bûye û di wateya vegotin ango destanê de ye. Di nav xwe de sir û efsûnan jî dihebîne (Nişanyan, 2020). Di nav gelê kurd de gelek caran ji dêvila peyva efsane "çîrok", hîkaye" û "mesele" jî têne bikaranîn. Li gorî Keskîn, kerametên evlîyayan ango "Qencên Xwedê" jî dikarin di vê çarçoveyê de bêne nirxandin (Keskin, 2019: 168). Li Avrupa ji birayên Grîmm û pê ve gelek folklorzanan hewl daye ku efsaneyan penase bikin. Li gorî Birayên Grîmm efsane, çîrokên derasayî ne. Li gorî, Gero von Wilpert efsane, ew çîrokên kin in ku di eslê xwe de ne bûyerên rast in lê wekî bûyerên rast têne pêşkêşkirin. Herweha ji guhdaran jî tê hêvîkirin ku ew jî efsaneyan wekî rastiyekê bipejirînin (Buch, 2006: 355). Folklornas Pertev Naili Boratav efsaneyan wekî "Perçeyên destanan ku ji aliyê dirêjbûn, xeml $\hat{u}$ huner ve ji destanan dûr ketine $\hat{u}$ tenê wek vegotinek derasayî ya derbarê kes ango rûdanekê di nav gel de mane." penase dike (Boratav, 
1969: 106). Digel ku heta niha gelek penaseyên efsaneyê hatiye kirin jî penaseyeke bi rêk û pêk nîne.

Ji W. Bascom bigrin heya bi M. Luthî gelek lêkolînerên ku li ser cudatiya di navbera cureyên vegotinên folklorî hûr dibin li ser mijarekê li hev kirine ku ew jî̀ di nav gel de ji bilî çîrçîrokan (fabl) hemû cure wekî bûyerên rastî têne bawerkirin. Ango, gel di çarçoveya vegotinên gelêrî de, lehengên çîrok, mît, efsane û hwd. wekî kesên rast ku di demeke kevin de jiyane, dihesibîne û bi hebûn û serpêhatiyên wan bawer dike (Oğuz, 2012: 55).

Wekî li jor jî hatiye behskirin, taybetiya herî berbiçav a ku efsaneyan ji cureyên çîrok, fabl û hwd. vediqetîne ew e ku digel berhemên xeyalî ne ji aliyê vebêjer û guhdaran ve wekî bûyer û qewimînên rast têne bawerkirin. Ji bo vegotina efsaneyan hostatiyeke zêde navê. Di jiyana rojane de efsane ji aliyê her kesî ve dikarin werin vegotin û parvekirin (Kvideland û Sehmsdorf, 1988: 14). Li her welatî ew rewş kêm zêde weha ye. Di hîmê wê de bawerî heye. Gel dixwaze ku ji wan bawer bike. Efsane derbarê rûdanên afirîna dinyayê heta bi cih, kes û bûyeran di gelek mijaran de têne vegotin. Efsane, hewl dide ku baweriya batil xûrt û zindî bihêle. Ji bo vê yekê jî gelek dane û delîlan dide ber guhdaran. Lewra hebûn û berdewamiya efsaneyan bi berdewamiya baweriya batil ve girêdayî ye. Heger bawerî ji holê rabe dê efsane jî wenda bibin ango bibin çîrçîrokek pûç ku tenê ji bo qerf û henekan têne vegotin (Mullen, 1971: 408). Her efsaneyek li ser tiştekî hatiye gotin lê taybetiya hevpar ew e ku, her efsane bi baweriyekê ve girêdayî ye. Lehengên efsaneyan kesên xwediyê hêzên nepen û derasayî ne (Amos, 1981: 97). Serpêhatî û gotegotên derbarê van lehengan de jî di asta derasayîbûnê de ne û di xeyala gel de roj bi roj mezin dibin û di nav gel de belav dibin. Taybetiyeke din a efsaneyan jî ew e ku, çîrokeke efsaneyen ya bi rêk û pêk tuneye. Nakokî her di nav efsaneyan de dijîn û niqaşên li ser efsaneyan kêm nabin (Degh, 2006: 204-205). Li gorî Mullen, her efsaneyek di nava xwe de baweriyeke gelêrî jî dihewîne. Ji ber vê yekê jî divê teqez li ser bê rawestîn. Ji ber ku baweriyên gel û efsane ne ji hev dûr in (Mullen, 1971: 410).

Efsane vegotinên kurt û zelal in. Digel ku efsaneyên herêma Semsûrê ji efsaneyên herêmên din ne kêmtir in, xebatên ku li ser vê herêmê hatine kirin gelekî kêm in. Wek mînak, di navbera salên 2000 û 2012an de li Tirkiyê di warê lêkolînên li ser vegotinên gelêrî de 68 tezên lîsansa bilind û doktorayê hatine amadekirin. Ji van 17 heb li ser efsaneyan e (Duman, 2013: 164). Li aliyê din em dizanin ku li Tirkiyeyê ji sala 2010 an û şûn ve, li bajarên wekî Mêrdîn, Diyarbekir, Mûş, Dêrsim, Çewlig û Wanê di bin banê beşên Ziman û Çanda Kurdî û Ziman û Edebiyata Kurdî de xebatên tezên lîsansa bilind hatin destpêkirin. Di navbera 2011an heta 2016an de 121 tezên lîsansa bilind ku mijara wan "Kurdolojî" ye hatine amadekirin. Ji wan, 109 heb bi zimanê kurdî (bi zaravayên kurmancî, kirmanckî/zazakî û 
soranî), 21 heb jî bi zimanê tirkî hatine amadekirin (Aykaç, 2017: 119-132). Ji van tezan 21 heb derbarê folklora kurdan de ne lê mixabin bi taybetî li ser efsaneyan tez nehatine amadekirin. Mebesta vê xebatê ew e ku wekî gaveke piçûk em dest bavêjin vê qadê.

Semsûr (Adıyaman), îro ji bilî navenda bajêr, ji 8 navçe, 19 bajarok û 453 gundan pêk tê ("Adiyaman il ilçe ve belde nüfusu", 2020). Semsûr, ji heyamên pêşîn heta niha bûye wargeha gelek civak, ol û nijadan. Hîtît, Hurî, Med, Mîtan, Asur, Pers, Komagene, Roma, Bîzans, Selçûqî û Osmanî hin ji wan şaristaniyan in (Toprak, 2018: 25). Li herêmê gelên kurd, tirk, ermen, ereb û sûryan ligel hev jiyane. Wan, ew mîrateya çandî ku di hezar salan de ketiye ser hev heta îro parastiye. Helbet vê çanda qedîm û kevnare gelek efsane jî bi xwe re anîne. Bi taybetî li gûnd û bejahiyên bajarê Semsûrê gelek efsane bi awayekî devkî di nav gel de hebûna xwe didomînin.

Qada vê xebatê herêma Komîrê ango Hemzik e. Bi qasî 25 kîlometroyan li bakurojhilatê Semsûrê ye. Herêm wekî çaleke fireh he û ji 10-15 gund û gundikan pêk tê. Derdora 10-15 hezar kes li vê herêmê dijîn. Gelê herêmê bi çandinî û sewalvaniyê ve mijûl dibe. Debara gelê herêmê piranî li ser hilberîna titûnê ye. Gelê herêmê bi zaravayê kurdîkurmancî dipeyive. Bi awayekî xwezayî efsane jî bi devoka kurmanciya Semsûrê têne vegotin. Herêma Komîrê (Hemzik) ji aliyê hejmar û cureyên efsaneyan ve dewlemend e. Li gorî agahiyên jêderan li herêmê di cureyên cihê de, bi qasî 28 efsaneyan têne gotin. Li jêr digel hewldana dabeşkirina efsaneyan ya li ser şopa Juha Pentikainen, nav û naveroka van efsaneyan jî bi kurtî hatiye vegotin.

Di vê xebatê de, piştî bi kurtî şîrovekirina penase û taybetiyên efsaneyan, hewldana nirxandin û tesnîfa efsaneyên herêma bajaroka Komîrê (Hemzik) ya girêdayî bajarê Semsûrê heye. Dane, bi rêbaza hevpeyvînên rû bi rû bi teknîka gogberfê hatine tomarkirin. Di vê çarçoveyê de, bi 21 kesên ku di vê mijarê de xwedî agahî ne re hevpeyvînên rû bi rû û hatiye kirin. Ji ber ku jêderan nexwastin nav û paşnava wan bêne eşkerekirin ji dêvila nav û paşnava wan remzên wekî "J1, J2... (Jêderê yekemîn, jêderê duyemîn....)" hatiye nivîsandin. Wekî din, agahiyên derbarê jêderan yên wekî temen, rewşa perwerdehiyê, cihê ku niha lê dijîn û hwd. di dawiya gotarê de hatiye rêzkirin. Agahî bi jêrenotan û amûrên dîjîtal hatine tomarkirin. Piştre, hemû agahî hatine deşîfrekirin û nirxandin. Ji ber sînorên rûpelên kovarê û pirsgirêkên devoka herêma Semsûrê me tenê cih da kurteyên van efsaneyan.

Ji ber ku rêbaza Pentikainen ya dabeşkirina efsaneyan hêsan û kêrhatî ye, di dabeşkirina (tesnîf) efsaneyan de rêbaza Juha Pentikainen hatiye tercîhkirin. Efsaneyên ku li herêma Komîrê (Hemzik) ya Semsûrê hatine tomarkirin jî di vê çarçoveyê de hatine nirxandin. 


\section{Xebatên Li Ser Dabeşkirina Efsaneyan}

Heta niha gelek kesan li ser efsaneyan xebat kirine û ji bo dabeşkirina efsaneyan hin rêbaz pêşkêş kirine. Lê derfetên vê xebatê rê nadin ku em behsa hemûyan bikin. Ji ber vê yekê jî êm ê li vir tenê behsa çend rêbazan bikin. Xebatên li ser efsaneyan hîmê wan digihêje xebatên Birayên Grîmm (Wilhelm:1787-1859; Jacop: 1785-1863). Her du birayan, ji 50 salî zêdetir li ser gelek cureyên folklorê xebatên tomarkirin, analîz, dabeşkirin û nirxandinê meşandine (Sokolov, 2009: 50). Piştî ku xebatên li ser efsaneyan zêde dibin, pêwîstiya dabeşkirina efsaneyan derdikeve holê. Lewre, karîgerî (fonksîyon) û dabeşkirina efsaneyan du pirsgirêkên têkilî hev in û her yek bi serê xwe nikare were nirxandin. Li Evropa, O. Dahnhardt, di navbera salên 1907 û 1912an de berhemeke qerase ya efsaneyan ku ji çar cildan pêk dihat amade kir. Hîmê wan li ser efsaneyên nava Încîlê bû. Di heman salan de (1912) Antti Aaarne, li ser dabeşkirina efsaneyên Fînî xebateke girîng weşand. Di vê çarçoveyê de gava herî berbiçav di sala 1966an de li Budapeşteyê hate avêtin. Wê salê, International Society Folk Narrative Research (Kongreya Navnetewî ya Lêkolînên Vegotinên Gelêrî) hatiye lidarxistin. Di kongreyê de ji bo tasnîfa cureyên efsaneyan a bi rêk û pêk biryara peywirdarkirina komxebatekê hatiye dayîn. Piştî xebatên hûr û kûr komxebat, encamên ku bi dest xistine wekî raporekê eşkere dike. Rapor ji aliyê kongreyê ve tê pejirandin (Nagy, 1998: 102). Ji ber ku derfetên vê gotarê bi sînor in, em dê li vir bi hûrgilî behsa vê kataloga efsaneyan ku hatiye amadekirin û binbeşên cureyên efsaneyan nekin lê bi kurtî em dikarin bibêjin ku di encama civînên komxebatê de efsane wekî, "efsaneyên derbarê afirîn û dawiya (qiyamet) dinyayê de", "efsaneyên derbarê dîrok û dîroka şaristaniyan de", "efsaneyên derbarê heyberên derasayî, hêzên derasayî, mîtolojîk" û "efsaneyên olî/efsaneyên derbarê xweda, xwedawend û lehengên olî" di bin çar serenavan de têne dabeşkirin (Alptekin, 2014: 22-23).

Hewldaneke tasnîfkirina efsaneyan jî ji aliyê Juha Pentikainen (1940-...) ve hatiye kirin. Pentikainen, li ser kevneşopiyên Fîniyan, çanda devkî ya Fînê xebitiye, doktoraya xwe li ser vê qadê kuta kiriye. Bi taybetî jî li ser efsaneya Kalavela û çanda Şamanîzmê xebatên gelek hêja kirine. Di xebatên xwe de lêkolînerê efsaneyan Carl-Herman Tillhagen wekî rêber hilbijartiye. Lewre bi gotina Tillhagen, "Efsane, helbest e, lê malê rastiyê ye û beşek ji jiyana rojane ye." Divê hîmê lêkolînên zanistî, li ser vê hişmendiyê were danîn (Pentikainen, 2006: 204-205). Pentikainen, ji bilî parzemîna Emerîqaya Başûr li hemû parzemînan xebatên qadê meşandine. Pentikainen, bi zanîn, çavdêrî, lêkolîn û tecrûbeyên xwe pişta xwe dide folklorzanê bi nav û deng Laurî Honko. Ew, efsaneyan li gorî berbelavbûna wan wekî 
"efsaneyên gerok" û "efsaneyên herêmî" dabeş dike. Efsaneyên herêmî, bi herêmekê hatine sînorkirin û hîn belav nebûne. Cerebe hîn nehatine şîrovekirin û li gorî kevneşopiyan nehatine guhertin. Pentikainen, vê astê wekî "numen" penase dike. Efsaneyên ku kêm-zêde li her herêmê têne vegotin û li gorî herêm û kevneşopiyan teşe girtine jî "efsaneyên gerok" in û xwediyê dîrokeke kevnare ne. Li gorî herêman dibe ku navê wan jî biguhere lê karakterê esas û gewdeyê efsaneyê naguhere. Pentikainen vê astê jî wekî "nomen" penase dike (Pentikainen, 1995: 46).

\section{Efsaneyên Gerok Li Herêma Komîrê (Hemzik)}

Li gorî rêbaza dabeşkirinê ya Juha Pentikainen, ji 28 efsaneyên ku li herêmê têne gotin 7 heb jê efsaneyên gerok in. Digel ku di navê efsaneyan de hin guhertinên piçûk hene, naverok û karîgeriya efsaneyên gerok gelekî dişibe hev. Di vê çarçoveyê de em dikarin bibêjin ku efsaneyên Ayzer Xefalî (Ebuzer -el Giffarî), Xoceyê Xizir û Kufte, Çiplax û Kufte, Pepûg, Gavanî Bûkê, Pêka Dûndilê û Elk/Pîra Xêw efsaneyên gerok in. Lewre ev efsane li gelek herêm û welatan têne vegotin. Wekî ji navê wan jî diyar dibe, 4 heb efsane derbarê kesayetên olî, 2 heb derbarê guherîna jinan ya ji bo kevir û çivîkan û yek jî̀ derbarê heyînên derasayî de ye. Kurteya van efsaneyan weha ye:

\subsection{Pêka Dûndilê}

Hz. Elî, hem ji ber ku zavayê Hz. Muhammed e, nifşa pêximber bi wî dewam kiriye û hem jî ji ber kesayetiya xwe û hêza xwe di nav alema îslamê de kesekî gelekî girîng e. Bi taybetî di nav civaka elewî de nirxeke wî ya gelekî bilind heye. Hz. Elî, tevî şûrê xwe û hespê xwe karaktereke efsanewî ye di heman demê de. Li gorî zanîn û baweriya gel, Hz. Elî di serdema pêşî ya îslamê de ji bo belavkirina misilmaniyê li gelek herêm û welatan şer kiriye. Ji ber vê yekê, di nav gel de derbarê hespê wî -Dûldûl- de gelek efsane hatine afirandin. Li gorî van efsaneyan, hespê wî (Dûldûl) hingî xûrt bûye şopa lingên wî li ser lat û tahtan çêbûye. Efsaneyên derbarê Dûldûlê di vê çarçoveyê de gerok in. Kurteya şaxeke vê efsaneyê ku li herêma Komîrê tê gotin weha ye:

"Pêka Dûldûlê, tahtekî pahn e û li hemberî gundê Girik, di nav zeviyekê de ye. Wexta ku meriv dihere Semsûrê li hêla jêr ya rê dimîne. Li ser wî kevirî, şopa simê Dûldûlê xûya dike. Dibêjin, dema ku Hz. Elî li qada şer hespê xwe (Dûndil) bezandiye sima wî li vî kevirî rast hatiye. Dûldûl hingî xûrt bûye, şopa simê wî li ser kevir çêbûye. Gelê herêmê wekî zîyaretekê diçe û wî kevirî û tawaf dike." (J3, Hevpeyvîna rû bi rû, 18 Çile 2021). 
Heman efsane li gelek herêman tê gotin. Wek mînak, li bajarê Denîzlî yê Tirkiyeyê kevirek heye ku pîroz tê pejirandin. Li gorî vê efsaneyê, dema ku Hz. Elî hespê xwe -wekî bifire- bi ser dijmin de ajotiye, lingekî hespê wî li wî kevirî rast hatiye. Şopa lingê wî li ser kêvir çêbûye (Türktaş, 2012: 63).

\subsection{Ayzer Xefalî (Ebuzer -el Giffarî)}

Ayzer Xefalî -li gorî efsaneyan- sencaxtarê artêşa îslamê ye ango al di dest de ye. Di dema Hz. Pêxember da artêşa îslamê hatiye herêmê da ku li hêrêmê misilmantiyê belav bike. Ayzer Xefalî jî yek ji eshabeyan e. Dibêjin, gotine (ji eshabeyan re):

- Kî dê sencaxê bigre û di pêşiya artêşê de here?

Ayzer Xefalî dibêje:

- Ez ê bigrim. Ê din dibêjin:

- Nabe, tu hîn piçûk î, hîn şeh di nav riha te re naçe. Ayzer Xefalî jî li ser vê gotinê radibe şehê di goştê rûyê xwe de diçikîne. Piştre radihêje sencaxê û tê şer. Şer dest pê dike, Ayzer Xefalî li cihê xwe yê ku aniha tirba wî lê ye derbê dixwe û şehîd dikeve (J4, Hevpeyvîna rû bi rû, 26 Mijdar 2020). Ev efsane jî yek ji efsaneyên gerok e. Lewra tê zanîn ku li Batman û Stenbolê jî bi heman navî tûrbe û ziyaret hene û li wan deveran jî heman efsane têne gotin.

\subsection{Pepûg}

Ev efsane li gelek deveran tê gotin. Di gelek waryantan de pepûg jin an zarokek e û piştî bûyereke xerab lava ji Xwedê dike da ku wê bike çivîkek. Ji ber dilovaniya wê diaya wê qebûl dibe û ew vediguhêze çivîkekê. Ew çivîk, li gorî herêman diguhere. Dibe kevok, qûmrî, dûvmeqes (hechecik), pepûg û hwd. (Yalçınkaya 2019: 946). Di waryanta ku li herêma Komîrê tê gotin de pepûg berê bûkek e, piştî zexta xezûrê xwe dibe çivîkek û bi çolê dikeve. Efsane, bi kurtî weha ye:

"Dibêjin, yekî bûkek aniye. Dem derbas bûye, bûk maye ducanî. Rojekê dilê wê goşt xwestiye. Feqîrî ye, kiriye nekiriye nikaribûye goşt bi dest bixe. Li malê cotek çaroxê xezûrê wê hene, wekî tê zanîn çarok ji çermê sewalan çêdibin, bûk radibe tayekî (ferek/ solek) çaroxan dixe avê, dikelîne û dixwe.

Êvar dibe, xezûrê wê tê malê. Dibêje:

- Ka fera çaroxa min? Her kes dibêje:

- Me fera çaroxa te nedîtiye. 
Xezûr diritimîne, bi israr li fera çaroxa xwe dipirse. Dawiyê de, xesû debare nake û mikûr tê. Dibêje, hal û meseleya bûka me ev e. Wê fera çaroxa te xwariye. Xezûr, hêrs dibe; radibe li bûkê dixe. Bûk dia dike, dibêje:

-Xwedêyo, bila bibûma çivîkek bi çolê biketima lê ez neketima vî halî.

Dibêjin, li ser vê diayê bûk di wê kêliyê de dibe çivîkek. Ji wê rojê û şûnde êdî hêlîna wê nav striyan e (J6, Hevpeyvîna rû bi rû, 23 Çile 2021).

\subsection{Xoceyê Xizir û Kufte}

Derbarê Xoceyê Xizir de li gelek welat û herêmên Rojhilata Navîn, heta li herêma Qafqasyayê jî gelek efsane têne gotin (Özcan, Çelik, 2020: 295-312). Li gorî baweriyê, Xoceyê Xizir nemir e. Mal û welatekî wî nîn e. Sal donzdeh meh gund bi gund, mal bi mal digere. Lê kes nizane dê kengî û di kirasê çi de derkeve pêşiya merivan. Her carê dikeve kirasê mirovekî. Car heye dikeve kirasê rawiran jî. Ew bixwe bereketê û zêdebûnê temsîl dike. Heger ew xweş bê pêşwazîkirin û dilê wî bê xweşkirin ew jî dê bereketê bixe nav wê malê. Heger kesek wî biêşîne dê Xoceyê Xizir nifirekê li wî bike ku ew û nif̧̧ên ji wî dê tu carî têr nexwin û xweşiyê û bextewariyê nebînin. Ji ber vê yekê bi taybetî di civakên elewî de pêşwazîkirin û hewandina mêvanan gelekî girîng e. Mêvan dibe, parsek dibe xem nake bi taybetî jî di meha rojiya Xoceyê Xizir de her kesê tê ber derî bi rûkenî tê pêşwazîkirin û destvala nayê şandin. Li herêmê derbarê Xoceyê Xizir de gelek efsane hene. Yek jê weha ye: "Dibêjin, kesekî ji gundê Omeran, ji jina xwe re gotiye:

- Jinik, îro mêvanekî min dike were. Tu jê re şîveke xweş amade bikî haa!

Piştî demekê karê mêrik derdikeve. Berî ku ji mal derkeve, berê xwe dide jina xwe, careke din hişyariyê didê, dibêje:

- Jinik, karê min derket, divê ez herim Semsûrê. Mêvanê min û wê şîreta ku min li te kiriye ji bîr nekî ha!

Jinik radibe ji bo wî mêvanî ku dê bê, kufteyan (kutilk) çêdike.

Piştî demekê yekî belengaz tê ber derî. Jinik ji xwe re dibêje, "Ev ne mêvanê ku mêrê min behsa wî kiriye. Ev hebe tunebê parsekek e." Radibe, xwe dide pêşiya beroşa kufteyan. Naxwaze ku mêvan beroşa kûfteyan bibîne. Mêrik, pirsa xwediyê malê dike. Jinik dibêje, "Mêrê min ne li mal e." Mêvan çendekî disekine. Jinik behsa şîvê û kutilkan nake. Mêvan hewl dide ku rabe. Jinik, di dilê xwe de dibêje: "Hey ez kufteyan nadim viya. Hema dîsa jî gune ye, ez ê du sê pahnikiyan " bidimê, bila birçî neçe." Mêvan pahnikiyan dixwe û diçe.

\footnotetext{
* Pahnikî: Xwarina ku tenê bi hevîrê kutilkan ê kelandî çêdibe.
} 
Dibe êvar, mêrê jinikê tê mal, dibêje:

- Jinik, mêvanê min hat, te şîveke xweş da ber?

Jinik dibêje:

- Welle, min tu mêvan nedîtin. Te got, min jî rabû kûfte (kutilk) amade kirin. Lê kesek nehat.

Tenê yekî belengaz wekî parsekan hate ber derî. Min jî du sê pahnikî dan ber $\hat{u}$ ew şand.

Mêrik li çokên xwe dixe, dibêje:

- Te malik li me xera kir. Ew mêvanê me bû, Xoceyê Xizir bû.

Ji wê rojê û pê ve ew mala têr naxwe. Heger bobelatên mezin nehatine serê wan, dîsa bi xêra wan çend pahnikiyan e." (J11, Hevpeyvîna rû bi rû, 27 Tîrmeh 2020).

\section{5. Çiplax û Kufte}

Ev efsane jî gerok e, navê lehengê efsaneyê li her herêmê diguhere. Li Balikesîrê "Alî Dede", li Bursa "Helvaci Baci", li Erziromê "Ahmet Baba", li Entabê "Şêx Bîlecen", li Dêrsimê "Munzir Baba", li Yozxatê "Alîyar", li Qersê "Hecî Kaxizman", li Malatyayê "Haci Yusuf" e (Şimşek, 2018: 528). Di nav gelek welat û çandan de bi hin guhertoyan tê gotin lê movika efsaneyê naguhere. Qencekî Xwedê heye. Xizan e û li ber destê axayekî, begekî şivantiyê dike. Axa (serdest) diçe Hecê, jina wî û şivan li mal dimînin. Rojekê jina wî xwarinekê çêdike. Xatûn, ji bo xwarina şîvê bang li şivanê malê dike. Hîn ku li ser şîvê ne, mêrê jinê tê bîra wê. Dibêje, "Xwezî axayê te jî li vir bûna. Wî ji vê şîvê pir hez dikir." Şivan, berî ku hilma li ser şîvê sar bibe wê digihîne axayê xwe. Axa, piştî ku ji Hecê vedigere sira şivan eşkere dike. Şivan bi carekê ve ji holê wenda dibe. Gelê herêmê li cihê ku şivan wenda bûye, li ser navê wî tûrbeyekê çêdike.

Li Semsûrê jî ziyareteke bi navê Çiplax (Ûryan Baba) heye. Naveroka efsaneyê kêm zêde wekî yên herêmên din e. Ev ziyaret, li gundê Selemûtê yê girêdayî Semsûrê ye. Li gorî efsaneya ku derbareyê Çiplêx de tê gotin, ew zilamekî gelekî baş û pak bûye. Li ba axayekî xulamtî kiriye. Li sewalên wî nihêrtiye. Ji bo ku dema veketinê pişt û laşê sewalan neêşê xwe tazî kiriye û xwe li erdê gindirandiye. Leqeba wî ya Çiplêx (tazî) jî ji wir tê. Efsaneya wî weha ye:

"Dibêjin, rojekê axayê wî dihere Hecê. Ew û jina axê jî li mal dimînin. Jinik kufta çêdike, bang li Çiplêx jî dike. Diwê:

- Xazikê axa jî li vir bûya. Wî pir li kufta hez dikir.

Çiplax dibêje:

- Xatûnê, dixwazî sanekê (teyfik-tebax) tije kufte bike ku ez bibim ji axayê xwe re. 
Jina axê, di dilê xwe de dibêje, "Qey fedi dike ki bibêje "kufta bide min" loma wisa dibêje." Sanikê tije kufte dike û dibêje:

- De were van kuftan bibe ji axayê xwe re.

Çiplax, radihêje kufta û dertê derve. Demekê û şûnde, axa ji Hecê vedigere. Vir da û wê da gel tê cem axê. Axa, bi tiliya xwe şivanê xwe nîşan dide û dibêje:

- Neyên cem min, herin cem wî. Çiplêx, heta Heccê kuftê bi germî anîn ji min ra.

Li ser vê gotinê, sirra wî (Çiplax) eşkere dibe. Ew jî bi carekê ve wenda dibe.” (J21, Hevpeyvîna rû bi rû, 25 Tebax 2020.).

\subsection{Elk/Pîra Xêw}

Elk ango pîra xêw, heyîneke nepen û bi efsûn e. Di hemû çandên Rojhilatî de heye. Jiyana wê li ser xwarina goştê mirovan e. Bi taybetî jî lebatên navgînî (kezeb, dil, gurçik û hwd.) yê jin û zarokan dixwe (Bane, Al (Elk), 2016). Li herêma Semsûrê wekî "Pîra Mer(iv)xwir jî tê naskirin. Li gorî hin jêderan, pîra xêw ango elk dijminê jinên çilînî û zarokan e. Carinan dikeve kirasê mêran û cilên sipî li xwe dike. Çavên xwe li derdorê digerîne, jineke bi tena serê xwe ya zêristanî li ku be xwe li wê û zarokê wê digre. Ew dizanin ku bi taybetî di çil rojê pêşî de zarok û dayik bê pergal in, qels in, wekî biwêja ku tê gotin, "tevir $\hat{u}$ bêr li kêleka wan e." Ji ber vê yekê jî gel ji hev û din re dibêje, "Jina zêristanî li malê bi tenê nehêlin." Li gorî baweriyeke din, divê di dema zêristaniyê de çilê jinan bi hev nekeve. Ango divê du jinên zêristanî neyên bal hev. Heger çilê wan tevlî hev bibe dê elk/pîra xêw li wan û zarokê wan bixe û bikûje. Ji bo ku rê li ber bobelatan were girtin heta ku ji wan tê nahêlin ku her du jin li hev rast bên, hev û din bibînin. Carinan ji neçarî, her du jinên zêristanî li hevûdin rast tên. Di demên weha de jin derziyên xwe bi hevûdin diguherînin. Heger derzî tune be bişkojeke ji qutikê (îşlig) xwe jê dikin û bi hevûdin diguherînin. Heger ew jî tune be ji kirasê xwe perçeyekî piçûk jêdikin û bi hevûdin diguherînin (Çifçi, 2019: 71). Di vê tevgerê de mebest xapandina hêzên nepen e. Herweha li gorî efsaneyan û baweriya gel pîra xêw ji hesin û ronahiyê ditirse. Ji bo vê yekê jî heta çil rojî lampe ango agir li mala jina zêristanî venamire; kêr, meqes, das, derzî û hwd. amûreke hesinî her li ber serê jina zêristanî û zarok e.

Derbarê elk/pîra xêw de gelek efsane têne gotin. Yek jê weha ye:

"Dibêjin, jineke zêristanî ji bo demeke kin zarokê xwe yê çilînî di hundir de tenê hiştiye û çûye derve. Dema ku vegeriyaye dîtiye ku elkê/pîra xêw, destê xwe daye ser devê zarokê di dergûşê de û hewl dide ku wê/wî bifetisîne. Heta ku jina zêristanî li derdora xwe amûreke hesinî digere, elk/ pîra xêw ji ber çavan wenda dibe. Jinik baz dide ser zarok lê dibîne ku zarok miriye." (J6, Hevpeyvîna rû bi rû, 23 Çile 2021). 


\subsection{Gavanî Bûkê}

Di gelek efsaneyên gerok de tê dîtin ku mirov (bi taybetî jî jin û bûk) di cih de hişk dibin û dibin kevirekî. Li gorî lêkolînên folklorî gelek sedemên vê yekê hene: Ji ber nifirekê, kiryareke xirab ango gunehekî, cezakirina evdan ya ji aliyê Xwedê ve, evînên nîvcomayî, neheqiya ku li jin û keçika hatiye kirin û hwd. (Sakaoğlu, 1980: 35).

Gavanî Bûkê ku bûye mijara efsaneyê, li nêzikî gundê Sarmikan ê girêdayî navenda Semsûrê ye. Bi qasî 6-7 kîlometroyan li bakûrê herêma Komîrê ye. Kevirekî mezin e û ji dûr ve dişibe peykerê bûkekê. Efsaneya wê weha ye:

"Dibêjin, di zemanekî pir kevin de, keçikek wekî bûk dane eşîrekê. Zewac bê dilê keçikê bûye. Eşîreke din jî xwe daye pêşiyê û nexwastiye ku ew dawet pêk were. Roja dawetê bûk li hespê siwar kirine û ji gund derxistine. Di navbera her du gundandan de eşîr hatine hemberî hev. Hindik maye ku eşîr li ser vê bûkê pevbiçin, şer bikin. Bûkê dia kiriye, gotiye: "Xwedeyo, tu min li vir bikî kevirekî û nekî para kesî. Bila ji bo min xwîn nerije." Diaya bûkê qebûl dibe û di cih de dibe kevir." (J13, Hevpeyvîna rû bi rû, 19 Tebax 2020).

\section{Efsaneyên Herêmî}

Bi qasî ku ji jêderan hatiye bihîstin, li herêma Komîrê (Hemzik) 21 efsaneyên herêmî têne gotin. Ji van efsaneyan 8 heb derbarê kerametên kesayetên olî, 3 heb derbarê avabûna êrikan (ziyaret), 3 heb derbarê dar û daristanan, 2 heb derbarê avabûna gundan, 2 heb derbarê hêza derasayî ya mirovan, 2 heb derbarê heyberên derasayî (Pîrevok) û 1 jî di derbarê bûyereke xwezayî ya awarte de ye. Efsaneyên herêmî ku li herêmê têne vegotin, bi kurtî weha ne:

\subsection{Avabûna Komîrê (Hemzik)}

Dibêjin, beriya niha bi 400-500 salî ji aliyê Dêrsimê kurdên koçer hatine vê herêmê. Konên xwe li derdora Pîrxûrkê (gundê Panavê) danîne. Li wir pezê xwe çêrandine. Ka çiqas li vir mane em nizanin, xortekî ji wan koçeran yê bi navê Hemze, li keçeke ji niştecihên wir hez kiriye. Piştre di navbera koçeran û niştecihên wir de gengeşî çêbûye. Hemze maye lê yên din dîsa bar kirine bi berjor de, ber bi Dêrsimê ve çûne. Hemze, li Komîrê maye û dev ji koçeriyê berdaye. Li vir zewiciye û ji wî zilamî bi navê Şeref, Sim, Hesen û Pewrik çar kur çêbûne. Piştre her kurek zewiciye û bûye malbatek. Ji wan malbatan çar eşîrên bi navê "Şerefk, Simêlk, Hesenk û Pewrik çêbûne. Îro ji her bavikî (êl) çend gund li herêmê ava bûne. Şeref(k) û (Î)Simêl(k), di cihê xwe de bi cih û war bûne û gundê Komîrê ava kirine. Ji Hesen, gundên Hesenka, Panav, Kanî Xela, Zorkûy, Malê Qasa, Malê Ûzerî Ûsiv, Malê Elî Ûsiv ava 
bûne. Pewrik, gundê Pewrikan ava kiriye. Hinek neviyê wan jî gundên Omeran, Narince, Malê Ber Dû, Malê Çawiş̧an û çend gundikên din ava kirine. Ji ber vê yekê ji herêma Komîrê re "Hemzik" jî tê gotin (J1, Hevpeyvîna rû bi rû, 23 Çile 2021).

\subsection{Gola Xwînê}

Gola Xwînê, navê deştekê û di heman demê de navê gundekî ye. Gund, bi qasî 7-8 kîlometroyan li başûrrojhilatê Komîrê ye. Li gorî efsaneyê, di demeke pir kevin de, li wê deştê du artêş (hin dibêjin Kaw û Reşî ne; hin jî dibêjin artêşa misilman û fileyan e) bi hev û din re ketine şerekî dijwar. Şer bi şev û rojan ajotiye. Hingî xwîn rijiyaye, deşt bûye gola xwînê û laşê kuştiyan bi ser xwînê ketine. Ji wê rojê û pê ve navê wir bûye Gola Xwînê. Piştî sal û zemanan, li wir dîsa bi wî navî gundek ava bûye. Ew gund hîn jî heye (J5, Hevpeyvîna rû bi rû, 25 Mijdar 2020).

\section{3. Çemê Milwalî}

Peyva "Çem", di devoka Semsûrê de ji wateya xwe ya eslî (ava ku diherike/rûbar) bêtir di wateya "devera avî û bi dar û ber" tê bikaranîn. Li herêmê ji bo ava mezin (çem-rûbar) ku diherike peyva "ça" tê bikaranîn. Di vê efsaneyê de jî bi vê wateyê hatiye bikaranîn. Ev çem (Çemê Milwalî), bi qasî 7-8 kîlometroyan li başûrrojhilatê gundê Komîrê ye. Bi ava çemê Xalbêrciyê û Kaniya Komîrê tê avdan. Li gorî efsaneyê, ev çem ji aliyê qencekî Xwedê yê nepen (Milwalî) ve tê parastin. Her kesê ku -qirşikekî be jî̀- bêyî destûra xwediyê wî erdî/darê, ji wir bîne mala xwe dê bobelatek mezin were serî.

Li gorî jêderekî, xalê wî piştiyek strî ji wir jêkiriye da ku bîne malê. Dema ku dike piştiyê striyan hilde ser milê xwe, kesekî xêw derdikeve meydanê. Dibêje, "Nebe, dibêjim ji te re." Xalê wî, guh nadê û striyan pişt dike, tîne malê. Wê şevê, xwediyê Çemê Milwalî, xwe dixe kirasê/dilqê marekî reş û xwe li stûyê xalê wî dişidîne. Dibêje, "Heger tu wan striyan serê sibehê nebî $\hat{u}$ daneynî cihê berê, ez ê aniha te bifetisînim." Xalê wî serê sibehê striyan dide ser pişta xwe û dibe, datîne cihê berê.

Dîsa li gorî efsaneyeke din ku jêder dibêje; Ew bixwe jî bûye şahidê wê ku agir bi her devera Çemê Milwalî ketiye, şewitiye. Lê belê roja din -wekî ku qet agir pê neketibe- her tişt dîsa bûye wek berê (J2, Hevpeyvîna rû bi rû, 18 Çile 2021).

\subsection{Kaniya Komîrê}


Dibêjin, eşîra Hînotê û ya Hemzik li ser dabeşkirina ava Kaniya Komîrê li hev nakin. Ji êvar da biryar didin ku roja dîtir bi hev û din re şer bikin. Her eşîrek amadekariyên xwe dike. Wê şevê baraneke zêde dibare. Serê sibehê her du eşîr jî radikin çekên xwe û diçin derdora kaniyê. Dibînin ku tahtekî (lat/zinar) mezin ji jor da hatiye û ketiye nava kaniyê. Av bûye du şet. Her kes matmayî dimîne. Baqil û malmezinên her du eşîran tên gel hev. Dibêjin, "Heger ew kevirê ewqas mezin îşev hatibe $\hat{u}$ av kiribe du şet, hîkmeta Xwedê ye. Bila her kes bi ava ku bi aliyê xwe ve diherike qayîl bibe." Li ser vê gotinê li hev dikin û dev ji şerkirine berdidin. Her kes vedigere mala xwe. Îro jî ava vê kaniyê bi heman rengî diherike û her kes bi para xwe ya avê qayîl e. (J2, Hevpeyvîna rû bi rû, 18 Çile 2021).

\subsection{Mala Pîrevokê}

Li gorî efsaneya ku li herêmê tê gotin, pîrevok ji aliyê teşe ve wekî jinekê ye. Mala wê di binê golan de ye. Pora wê û pêsîrên (memik) wê digihêjin erdê. Kuvî ye, lê belê heger şûşin di pêsîrên wê de bê çikandin kedî dibe. Careke din nikare kuvî bibe û vegere dinyaya xwe, binê golê. Ji ber ku êdî ji aliyê meriv û malbata wê ve naye pejirandin. Tiştê ku destê wê pê bibe, bereket dikeve navê. Li gorî jêdera me efsaneya pîrevokê weha ye:

"Li vê derê malek heye. Mala "A"* dibêjin. Çûne nav çêm/erd, mêzikirine ku jineke pora wê dirêj, pêsîrên wê digihêjin erdê li wir e. Jinik girtine, birine mala xwe. Ji xwe re kirine qewraş. Jinik (pîrevok) nesekiniye, tim ji mala wan reviya ye. Wan jî her carê ew girtiye. Dawiyê de yekî şûjinek di pêsîrên wê re kiriye. Piştre heta demeke dirêj li mala wan sekiniye. Ka çiqas dem derbas dibe, kes nizane. Xwediyên malê xwestine wê azad bikin, ji mala xwe derînin. Ziman ketiye dêv $^{* *}$ gotiye, "Min bernedin, heger ez herim dê $\hat{u}$ bav, xwuşk $\hat{u}$ birayên min dê min bikujin." Xwediyên malê, guh nedane van gotinên pîrevokê û ew birine diyarê goleke kûr. Pîrevokê careke din berê xwe daye mezinê makê. Gotiye: "Ez ê niha xwe berdim binê golê. Heger xwîn bi ser avê neket, zanibin ku malbata min ez qebûl kirime; na heger xwîn bi ser avê ket, zanibin ku wan ez kuştime." Berî ku xwe berde binê golê nifirekê jî li wan dike. Dibêje, "Şalmê (ma şalê) hûn dirêj nebin!"* Pîrevok xwe davêje binê golê. Xwîn bi ser avê dikeve. Ji wê rojê û pê ve heger malên wan çar bin nabin pênc. Ango serjimara (nifûs) wan zêde nabe." (J5, Hevpeyvîna rû bi rû, 25 Mijdar 2020).

\footnotetext{
* Ji ber nazikiya mijarê me nexwest ku navê wan malbatan eşkere bikin. Lewra, kur û neviyên wan hîn li heyatê ne.

** "Ziman ketiye dêv" biwêj e. Wate, dest bi axaftinê kiriye. Peyva "dev" di dema axaftinê de carinan ditewe û wekî "dêv" tê gotin.

*Wate, bila berê we, malbata we fireh-zêde nebe.
} 


\subsection{Destê Pîrevokê}

Li gorî baweriya gelê herêmê, destê pîrevokê bi çi bibe, bereket dikeve nav wî tiştî. Destê pîrevokê bi kê bibe, bereketa xurekên wê malê zêde dibe. Ew yek bi rêya xewnan be jî dibe. Efsaneyeke derbareyê bereketa destê pîrevokê ku li gundê Narinceyê tê gotin weha ye:

"Dibêjin, li Narincê mala "D" hebûye. Malbata wan gelekî feqîr bûye. Rojekê kebaniya malê di xewna xwe de pîrevokekê dibîne. Pîrevok tiştên xwarinê jê dixwaze. Ew jî bi qasî ku heye xûrekên xwe bi wê re parve dike. Pîrevok, wekî malavahiyê, destê xwe li milê wê dide. Piştî wê rojê, digel hemû tengasiyan qûtê mala wan naqede. Kebaniya malê destê xwe bi çi bike, bereket dikeve nav wî tiştî." (J12, Hevpeyvîna rû bi rû, 10 Mijdar 2020).

\section{7. Êrikî (Ziyareta) Komîrê}

Li gorî efsaneyê, Şah Ahmet û Şah Mehmet du bira ne, ji bo belavkirina ola Îslamê, ji aliyê Misirê hatine Komîrê. Piştî demekê Şah Ahmet çûye aliyê Sêwazê lê Şah Mehmet li Komîrê maye. Li tenişta wê kaniyê bi cih û war bûye. Piştî ku miriye, gelê herêmê ew li pişta Kaniya Komîrê veşartiye û li ser gora wî tûrbeyek çêkiriye (Çetin, 2007: 25-26). Gel, di demên cuda de diçe serdana tûrbeya wî. Li wir qurbanan serjê dike, loqmeyan belav dike û diayan dike. Bi taybetî di salên ku baran kêm dibare keç, bûk û jinên gund diçin ber vî êrikî. Piştî ku loqme tê çêkirin, xwarin û belavkirin keçik dadikevin ser kaniyê û avê direşînin ser hev û din. Wisa tê bawerkirin ku piştî vê rê û rismê dê -bi alîkariya Şah Mehmedê Misrîbaran bibare (J2, Hevpeyvîna rû bi rû, 18 Çile 2021).

\section{8. Êrikî Şêxella (Şeyxûlla)}

Li gorî jêderan, navê wî yê rastîn Mehmed Elî ye. Piştre gel navê wî kiriye Şêxella (Şêyxulla). Ew, yek ji pêşengên mezheba elewîtiyê ye. Li gorî efsaneya ku tê gotin, dema ku pêşengên Îslamê hatine herêmê û li wir bi şopdarên olên din re şer kirine, pir birçî bûne lê tiştekî wan ê xwarinê nemabûye. Di wî deraxê/delava teng de hirmiyên gewrik ji wan re bûne xûrek. Mehmed Elî (Şêxella) jî gotiye, "Heta dinya heye, bila hirmî li vir hebin." Ji ber vê yekê, tu caran darên hirmiya gewrik li wir naqedin. Qet nebe şitlên hirmiyan li wir hene." (J4, Hevpeyvîna rû bi rû, 26 Mijdar 2020).

\subsection{Ziyareta Kulikreş}

Ew Ziyaret bi qasî kîlometreyekê li başûrê gundê Narinceya Komîrê ye. Dareke tuyê di navenda ziyaretê de heye. Li ber dara tûyê Kevirekî mezin heye û çend kevirên piçûk jî li ser wî kevirî ne. Dora ziyaretê bi dîwarê keviran hatiye parastin. Li gorî efsaneyê, jineke şivan 
pezê xwe li wê derdorê diçêrîne. Jineke din a ji wî gundî jî di wir re derbas dibe. Ji jina şivan re dibêje, "Pezê xwe hinekî wê de bibe, bila nekeve hewşa ziyaretê." Şivan guh nadê, dibêje: "Hûn jî kevirekî li ku bibînin, maçî dikin û dibêjin ev ziyaret e." Di wê kêliyê de beranek ji nav pez diqete û tê bi qûloçan li nava pişta wê dixe. Jinik dikeve erdê û dimire. Ji ber tiştên weha kes newêre zirarê bide wê ziyaretê û pozeyî Narincê." (J2, Hevpeyvîna rû bi rû, 18 Çile 2021).

\subsection{0. Şopa Destê Ap Eyîzế*}

Ap Eyîz ango Ap Ezîz, yek ji dedeyên elewiyên Semsûrê ye. Ap Eyîz, ji ocaxê Axûçan e. Li gundê Bilamê yê girêdayî navçeya Cêlikan hatiye dinyayê. Piştre, li gelek gundan geriyaye û rê rismên demê/cemê li dar xistiye. Gelek salan li gundê Şexmîran (Şax Mîran) jiyaye û di sala 1966an de li wir wefat kiriye. Li wir hatiye veşartin. Li derdora gora wî tûrbeyek hatiye çêkirin. Kesên ku şîfayê dixwazin, îro jî diçin mala kurê wî di tasa ku ji Ap Eyîzê maye de avê vedixwin (Çifçi, 2019: 88). Gelê herêmê di demên cuda de-piranî payîzê- diçe gora wî ziyaret dike, dia dike û qurbanan dide. Li herêmê behsa gelek kerametên Ap Eyîzê tê kirin. Yek jê weha ye:

"Jineke ku zarokê wê çênabin, diçe bal Ap Eyîzê. Ap Eyîz, li malekê ye û demê/cemê digerîne. Ap Eyîz, mebesta hatina jinikê fêm dike. Bang li jinikê dike. Berî ku jinik devê xwe veke û ricaya xwe bike, dede destê xwe li pişta wê dide. Dibêje, "Here keça min, bi ya Xwedê, dê miradê te bibe." Piştî demekê jinik ducanî dimîne. Dema ku zarok çêdibe, dibînin ku li ser pişta zarok şopa destê Ap Eyîzê heye." (J9, Hevpeyvîna rû bi rû, 15 Tîrmeh 2020).

\subsection{Nifira Dêde (Dede)}

Li herêmê di nav gel de gotineke weha heye. Dibêjin, "Xwe ji nifirên dedeyan biparêzin. Nifirên wan zû qebûl dibin." Li herêmê derbarê gelek malbatên ku rastî nifirên dedeyan hatine de efsane têne vegotin. Yek jê weha ye:

"Dibêjin, rojekê "B" û hevalekî xwe diçe ku dêde bikuje. Dema ku dede çav li wan dike, dibêje:

- Heger hûn bi çi mebestê hatibin, dev jê berdin; vegerin mala xwe.

Ew koma xortan vedigere malê lê piştî çend rojên din dîsa dikevin nava hewldanan. Diçin ku dede bikujin. Dede li yekî ji wan xortan vedigere, dibêje:

\footnotetext{
* Li herêma Semsûrê, navê Ezîz/Azîz tê tewandin û wekî Eyîz tê bilêvkirin. (T.Ç).
} 
- Ez tu diayan li we nakim; here, şalmê (ma şalê) hûn -mala "E"- neyên ser hev. Yeka we nebe dudu.

Piştî wê rojê ew malbat qet nayê ser hev, du bira nayên gel hev; karê wan rast naçe, qet têr naxwin." (J10, Hevpeyvîna rû bi rû, 26 Tîrmeh 2020).

\subsection{Kerrê Kawî û Şiva Hişk}

Ew "qencê Xwedê" ji eşîra Kaw e û ji ber ku guhê wî hinekî giran bûye, jê re gotine "Kerrê Kawî". Gora wî li gundikê Gomê Silikan e. Bi qasî 35 kîlometroyan li bakurrojhilatê Semsûrê ye. Derbarê kirametên Kerrê Kawî de gelek efsane hene. Yek jê weha ye:

"Dibêjin, berê feqîrî pir bûye û têkberên paqijiyê (sabûn, deterjan û hwd.) jî tunebûne. Gel bi xweliya (arî) êzingan kinc/cil û bergên xwe şûştine. Kerrê Kawî, jî rojekê barek xwelî (arî) biriye deştê. Di rê de du xortên ji eşîra Îzol hatine pêşiye. Gotine:

- Kerro! Dibêjin kirametên te hene. Ka ji me re jî kirametekê binimîne ku em jî ji te bawer bikin.

Kerrê Kawî, deng ji xwe biliye û wekî ku nebihîstibe li pey barê xwe meşiyaye. Xort, careke din hatine pêşiya wî û ritimandine. Careke din heman daxwaz kirine. Kerrê Kawî mêze kiriye ku xelasî ji wan tuneye. Di wê kêliyê de şiveke hişk di dest wî de bûye. Ew şiva hişk di erdê de çikandiye. Gotiye:

-Heta ku ez ji deştê vegeriyame heger ew şiva hişk şîn hat, qey tiştekî (keramet) min heye. Na, heger şîn nehat, hûn jî ji min bawer nekin.

Dibêjin heta ku ew ji deştê vegeriyaye -bi emra Xwedê- ew şiva hişk şîn hatiye. Ew dara hîn jî li biniya gundê Mazêlê ye û ter e." (J7, Hevpeyvîna rû bi rû, 20 Tîrmeh 2020).

\subsection{Kerrê Kawî û Goşiyê Tirî}

Dîsa li gorî efsaneyeke din, Kerrê Kawî di dema rezbirrîna de (dawiya sibatê-serê adarê), li nav rez bûye. Tevî çend gundiyan rezê xwe dibirre. Hin ji wan gundiyan gotine: "Kerro, dibêjin tu xwediyê kirameta yî. Ka ji me re du-sê goşî tiriyê teze bîne." Kerrê Kawî, hinekî ji wan dûr ketiye. Piştî kêliyekê tevî çend goşî tirî hatiye cem gundiyan. Hin ji wî tirî dixwin; hin jî naxwin. Ê ku dixwin, dimrin; ê ku naxwin jî dimînin (J8, Hevpeyvîna rû bi rû, 22 Tebax 2020).

\subsection{Mamkwîr û Xortên Komîrî}

Navê wî yê rastî Mehmûd e. Lê belê ji ber ku çavekî wî hinekî kêm dîtiye wekî nasnav "Mamkwîr" gotine jê re. Ew bi xwe ji gundê Komîrê ye. Du kurên wî û gelek neviyên wî hîn 
sax in. Mamkwîr, bi hêz û wêrekiya xwe bi nav û deng bûye. Derbarê hêza wî de gelek serpêhatî wekî efsane têne gotin. Yek jê weha ye:

"Li pişta gundê Komîrê (bakurê gund) çiyayekî asê heye. Rojekê Mamkwîr û heft-he(y)şt xortên gund diçin çiyê da ku êzingan bibirrin û bînin malê. Dema ku ji gund dûr dikevin, xort bela xwe di Mamkwîrê didin. Dibêjin:

- Ap Mamo, dibêjin tu yî pihêt (xûrt/xwedî hêz) î. Ka pihêtiya xwe nîşanî me jî bide.

Mamkwîr, dike nake xort bela xwe ji wî venakin. Li ser vê yekê Mamkwîr dibêje:

- Ez ê herim ser vî tahtê han. Li ser piya bisekinim. Hûn jî werîsekî bi nava min ve girêdin $\hat{u}$ hemû bi hev re bikşînin. Heger we ez ji wir anîm xwarê, hûn çi dixwazin serbest in. Lê heger hûn nikaribin min bînin jêr, hûn dê barê xwe yê êzingan bînin ber mala min vala bikin.

Xort, werîs li nava wî girê didin û bi hev re dikşînin. Dikin nakin nikarin Mamkwîrê ji ser wî tahtî bînin xwarê. Piştre, diçin bal wî bi heyirî li çaroxên wî dinihêrin. Dibînin ku çermê serê hemû tiliyên wî yê lingan rabûye û çaroxa wî tije xwîn bûye. Barê xwe yê êzingan tînin li ber mala wî vala dikin." (J14, Hevpeyvîna rû bi rû, 23 Çile 2021).

\subsection{Mamkwîr û Barê Hêstirê}

"Dibêjin, rojekê Mamkwîr diçe nav erdê xwe. Daran dibire û li hêstira (qantir) xwe bar dike. Radihêje hefsarê hêstira xwe û berê xwe dide malê. Di rê de, hêstira wî tevî barê li ser piştê di heriyê de dimîne. Dike nake nikare derkeve. Mamkwîr her du destên xwe dide bin zikê hêstirê û tevî barê li ser ji heriyê derdixe û datîne cihekî zûha. Dibîne ku her deh tiliyê destên wî jî zikê hêstirê qul kirine. Hêstir di cih de dimire." (J15, Hevpeyvîna rû bi rû, 25 Tîrmeh 2020).

\subsection{Ap Eyîz û Mendî Çûk}

"Dibêjin, Mendê Çûk ${ }^{*}$ û hevalên xwe diçin ku Ap Eyîzê bikujin. Diçin devê deriyê mala ku Ap Eyîz lê dimîne. Ap Eyîz, mebesta wan fêm dike, dibêje "Di cihê xwe de bisekinin." Mendê Çûk û hevalên xwe di cihê xwe de hişk dibin. Dikin nakin nikarin xwe tev bidin. Piştî demekê Ap Eyîz dibêje, "Herin, bela xwe bibînin." û wan berdide. Piştî vê bûyerê Mendê Çûk korocax dimîne. Her hevalekî wî jî bobelatek tê serî, dimrin." (J17, Hevpeyvîna rû bi rû, 15 Çile 2021).

\footnotetext{
* Li herêma Semsûr û Komîrê dema ku navê mirovan bi devkî tê gotin, tê kurtkirin ango xerakirin. Di vê mînakê de navê zilam "Mehemed" e lê belê di nav gel de wekî "Mend" tê vegotin. Her weha nasnav û zirnav (laqab) jî têne kurtkirin. Di vê mînakê de peyva "piçûk" wekî "çûk" hatiye vegotin. Li herêmê mînakên vê yekê gelek in. Wekî Ûs (Ûsiv), El (Elî), Mist (Mistefa), Zêw (Zeyneb) û hwd.
} 


\subsection{Ap Eyîz û Seydik Dede}

"Li gorî gotegotan, wexta ku Ap Eyîz dimire gel li dora tabûta wî dicive. Yek ji wan, dibêje, "Dede, tu xwediyê kerametan î. Ka ji me re kerametekê binimîne." Pismamekî Ap Eyîzê bi navê "Seydik Dede" heye, ew destê xwe li tabûtê dixe. Di wê kêliyê de tabût ji erdê bilind dibe û dîsa dadikeve. Seydik Dede, dibêje "Ev nebû, yeka din." û dîsa destê xwe li tabûtê dixe. Vê carê erd û asîman li hev diqelibe, erd dihêje; şev û roj ji bo demeke kin cih diguherîne (J18, Hevpeyvîna rû bi rû, 8 Tebax 2020).

\subsection{Ap Eyîz û Tûrê Şêkir}

Ev efsane jî derbarê kiramet û nifirên dedeyên mezheba Elewîtiyê de ye. "Dibêjin, Ap Eyîz diçe malekê. Dibêje:

- Hûn dikarin çayekê bidin min?

Mazûban jî dibêje:

- Dede were, çay jî heye; şekir jî heye.

Piştî demekê çayekê tînin lê şekir nayînin pêşiya dêde. Dede dibêje:

- Ka şekirê we?

Jina mazûban, naxwaze ku şekirê xwe bide dede. Di dilê xwe de dibêje "Şekir tuneye." Dede du sê caran dubare dike lê şekir nayê. Dede ji jina mazûban re dibêje:

- Keça min, here xanîmalê* binêre ka şekir heye ya tuneye?

Jinik radibe, bê dilê xwe diçe xanîmalê. Berê şekirê hûr di tûrê kekebêzi de difirotin. Devê tûrê şekirê bîst kîlo vedike. Dibîne ku hemû bûye ax." (J19, Hevpeyvîna rû bi rû, 08 Tîrmeh 2020).

\subsection{Ap Eyîz û Marê Reş}

Mar, bi taybetî jî marê reş di gelek çandan de heye û wekî lawirekî taybet tê hesibandin. Wek mînak, di çanda Sûmeriyan de mar wekî lawirê ku giyayê dermanê nemirinê ji Gilgamêş diziye û xwariye tê pêşkêşkirin (Eliade, 2003: 99). Di çandên Qafqasyayî de mar, xêr û bereketê bi xwe re tîne, naye kuştin (Biray, 2013: 95-113). Di çanda Şamanîzmê de, ji bo ku mirov bi pêşerojê zanibe, divê bi zimanê çivîkan zanibe. Ev yek jî bi xwarina marekî ango sewaleke din ya bi efsûnî pêk tê (Eliade, 1999: 126). Li gorî efsaneya Şahmaranê, mar ji navê berjor jineke gelekî xweşik e û mala wê di binê erdê de ye. Nemir e û hemû mar di bin emrê wê de ne. Kirasguhertina maran û serdemên guherîna jinan (wekî rojên grîng, ducanîbûn,

\footnotetext{
* xanîmal: Peyveke resen a kurdî ye, odeya ku firaq, qût û xwarin lê ne û şîv lê çêdibe, mitbex.
} 
menopoz û hwd.) wekî remzên hevpar xûya dikin (Yeşildal, 2018: 420-431). Piranî wekî lawirekî pîroz tê hesibandin. Gelek caran xerabiyê temsîl dike. Lê carinan jî -wekî herêma Semsûrê- marê reş wekî lawirekî baş tê hesibandin. Li gorî baweriya gelê herêmê, marê reş bi mirov venade. Ji ber ku dostê mirovan e. Zêrevaniya erd û milkê gel dike. Qencên Xwedê hikimê li maran jî dikin. Derbarê Ap Eyîzê û maran de gelek efsane hene. Yek jê weha ye:

"Du heb gundî diçin ku herin bal Ap Eyîzê. Di rê de li marekî rast tên. Her du heval, bi hezar zor û zehmetiyê wî marî dikûjin. Piştre, riya xwe didomînin. Dema ku digihêjin bal Ap Eyîzê berî ku ew tiştekî bibêjin, dede ji wan re dibêje: "Werin berxên min, werin. Serî di dest min de bû, we jî li boçikê dixist" (J20, Hevpeyvîna rû bi rû, 20 Çile 2021).

\subsection{Dara Benavê}

Li gorî efsaneyê, ew tîra ku li ser nimêjê Hz. Elî dikuje ji dara benavê hatiye çêkirin. Li ser vê bûyerê Xwedê, wek cezayekî, ber û fêkî ji dara benavê re heram kiriye. Ji wê rojê û heta roja qiyametê ew dar nifirî ye û dê bê ber bijî. Ji ber vê baweriyê ye ku di nav Kurdên Kurmanc de, darên ku fêkiyê wan nîne wekî "dara bênamûsê" têne penasekirin (J5, Hevpeyvîna rû bi rû, 25 Mijdar 2020).

\subsection{Dara Gulmadê}

Li gorî efsaneyê, dibêjin berê li derdora gundê Hesenkan jineke bi navê "Gulmad” hebûye. Gûlmad, bê mal û malbata bûye. Derbarê wê de kesî tiştek nezanibûye. Gulmad li çolê, li nav erd, dar û bestan de jiyaye. Di wê demê de li nêzikî gund dareke mezin a pelgê/çinarê hebûye. Demsala havînê, şivanan ji bo bêriyê û mexeldanê pez anîne bin vê darê. Her ku jin û keçên gund hatine bêriyê, Gulmadê jî alîkariya wan kiriye. Gundiyan jî hinek şîr û pêdiviyên din dane wê. Rojekê Gulmad nexweş ketiye û miriye. Gundiyan ew li tenişta goristana gund, li bin dara guvîjê veşartiye. Dibêjin, destê Gulmadê dermanê zerikê bûye. Heta demeke nêzîk jî gelê herêmê ji bo nexweşîna zerikê axa bin wê darê dianî, dixist nav avê û vedixwar (J16, Hevpeyvîna rû bi rû, 20 Tîrmeh 2021).

\section{Encam û Pêşniyar}

Piştî vê xebatê, encamên ku hatine bidestxistin bi kurtî weha ne:

- Efsaneyên ku hatine tomarkirin ji aliyê teşe, cure û motîfan ve xwediyê karaktereke gerdûnî ne.

- Efsane, beşeke girîng ya çanda devkî pêk tînin. Ji hezar salan û vir de di nav gel de hatine gotin û ji nifşekî derbasî nifşê din bûne. 
- Ji efsaneyên ku hatine tomarkirin, 7 heb jê efsaneyên gerok in; 21 heb jî efsaneyên herêmî ne. Efsaneyên gerok piranî derbarê kesayetên olî de ne.

- Li herêma Komîrê (Hemzik), ji bilî efsaneyên derbarê avabûn û xerabûna dinyayê mînakên hemû cureyên efsaneyan hene. Bi taybetî jî efsaneyên derbarê kesên olî (Qencên Xwedê) û heyberên derasayî de zêdetir in.

- Di encama lêkolîn û çavdêriyan de derkete holê ku di sazkirina têkiliyên civakî û çanda hevpar ya gel de efsane roleke girîng hildidin ser milê xwe. (Efsaneya derbarê parvekirina ava Kaniya Komîrê de, mînaka vê yekê ye.)

- Yek ji taybetiyên efsaneyan ew e ku efsane hinek sînoran di navbera xweza û mirovan de datînin. Bi xêra van efsaneyan mirov bi rêzdarî (û hinekî jî tirs û xof) nêzikî xwezayê dibin. Ji dayîna xisarê ya ji dar, kevir, sewal, av, kanî û hwd. xwe didin paş.

- Piraniya efsaneyan ji aliyê mêran ve têne gotin lê belê efsaneyên derbarê "Qencên Xwedê" ango kesayetên olî de ji aliyê jinan ve girîngtirîn têne dîtin.

- Efsane, bi zagonên xwe yên nenivîsandî, jiyana rojane bi rêk û pêk dikin û bi vî rengî piştgiriyê didin jiyana hevpar.

- Efsane li ser derûniya kes û civakê hem erênî hem jî̀ neyînî dikarin bandorê bikin. Lê belê piranî bandoreke erênî dikin. Bi gel re, bi alîkariya efsaneyan xwemalîbûn (nasnameya civakî) çêdibe.

- Hate dîtin ku efsane, di warê têgihiştina tevna çandî ya civaka kurd de xwediyê roleke girîng in û wekî nirx û mîrateya hevpar ya gel hebûna xwe didomînin.

- Efsane, di nava xwe de gelek hêmanên zimanî dihebînin. Efsane, ji aliyekî ve paşxaneya hişmendiya civakê diyar dikin, ji aliyê din ve jî ziman diparêzin. Bi mirina her efsaneyê gelek nav û peyvên kurdî jî wenda dibin. Ji bo naskirina hişmendiya civaka kurd û parastina zimanê kurdî divê efsane werin tomarkirin; şîrove û nirxandinên kur li ser wan bêne kirin. Mixabin nifşên ku bi teknolojiya dîjîtal mezin dibin hay ji van efsaneyan nîn in. Ew jî xetereya wendabûna çanda devkî bi xwe re tîne. Ji ber vê yekê bi mebesta parastin û jiyandina mîrateyên ne şênber yê gelê kurd, hêja ye xebatên bi vî rengî bêne domandin.

\section{JÊDER}

Adıyaman İl, İlçe, Belde Nüfusu. (20 Çile 2021). http://adiyaman.gov.tr/il-ilce-ve-beldenufusu.

Alptekin, AB. (2014). Efsane ve Motifleri Üzerine. Ankara: Akçağ Yayınevi. 
Amos, DB. (1981). Folklore Genres, Texas: University of Texas Press.

Aykaç, Y. (2017). Bîbliyografyaya Tezên Beşên Kurdolojiyê yên li Tirkiyeyê (2011-2016).

The Journal of Mesopotamian Studies, 2(1), 119-132.

Bane, T. (2016). Encylopedia of Giants and Humanoids in Myth, Legend and Folklore, Nort

Carolina: Mc Farland Company, İnc, Publishers.

Biray, N. (2013). Terim Dünyamızda Yılan: Kavram, Anlam ve Yapı Bakımından. Avrasya Terim Dergisi, 1(2), 95-113.

Boratav, PN. (1969). 100 Soruda Türk Halk Edebiyatı, İstanbul: Gerçek Yayınevi.

Buch, W. (2006). Masal ve Efsane Üzerine. (çev. Ali Osman Öztürk). Halk Biliminde Kuramlar ve Yaklaşımlar 1 içinde (354-362). ed. Oğuz, MÖ, Ekici, M., Özdemir, N., Öğüt Eker, G., Gürçayır, S., Ankara: Geleneksel Yayınları.

Çetin, N. (2007). Adıyaman İli ve Çevresindeki Manevi Halk İnançlarının Dinler Tarihi Açısından Değerlendirilmesi. (Teza lîsansa bilind ya çapnekirî). Selçuk Üniversitesi Sosyal Bilimler Enstitüsü, Konya.

Çifçi, T. (2019). Adıyaman ve Çevresinde Halk İnançları ve Halk Hekimliği (Baweriyên Gelêrî û Dermanê Kurmancî li Herêma Semsûrê). (Teza doktorayê ya çapnekirî). Dicle Üniversitesi Sosyal Bilimler Enstitüsü, Diyarbakır.

Çifçi, T. (2019). Kürt Halk Hekimliği, Tedavi Yöntemleri ve Ocaklık Kültürü: Adıyaman Örneği. Bingöl Üniversitesi Yaşayan Diller Enstitüsü Dergisi, 5(10), 75-100.

Dêgh, L. (2006). Günümüz Bağlamında Efsane Üzerine Teorik Bir Düşünme ve Efsanenin Tanımı. (çev. Selcan Gürçayır). Halkbiliminde Kuramlar ve Yaklaşımlar 1 içinde (203-234). ed. Oğuz, MÖ, Ekici, M., Özdemir, N., Öğüt Eker, G., Gürçayır, S., Ankara: Geleneksel Yayınları.

Duman, M. (2013). Türkiye'de 2000-2012 Yılları Arasında Halk Bilimi Alanında Hazırlanan Doktora Tezleri Üzerine Bir Değerlendirme. Millî Folklor, 25(99), 159-174.

Eliade, M. (1999). Şamanizm. (çev. İsmet Birkan). İstanbul: İmge Yayınevi.

Eliade, M. (2003). Dinsel İnançlar ve Düşünceler Tarihi. Cilt 1. (çev. Ali Berktay). İstanbul: Kabalcı Yayınevi.

Keskin, N. (2019). Folklor û Edebiyata Gelêrî. Stenbol: Weşanên Avesta.

Kvideland, R., \& Sehmsdorf, H. K. (1988). Scandinavian folk belief and legend (Vol. 15). University of Minnesota Press.

Mullen, PB. (1971). The Relationship of Legend and Folk Belief. The Journal of American Folklore, 84(334), 406-413. 
Nagy, I. (1998). Classification of Origin Legends. In Die heutige Bedeutung oraler Traditionen/The Present-Day Importance of Oral Traditions (pp. 307-314). VS Verlag für Sozialwissenschaften.

Nişanyan, S. (2020). Efsane, di nav Nişanyan Sözlük de. (10 Îlon 2020) https://www.nisanyansozluk.com/.

Oğuz, MÖ. (2012). Karacaoğlan: Anlatıcılar ve Biyografiler. Millî Folklor, 24(93), 53-61.

Pentikainen, J. (1995). Efsanenin Yapısı ve İşlevi. Wergera ji bo Tirkî: İsmail Görkem. Milli Folklor, 25, 46-56.

Sakaoğlu, S. (1980). Anadolu-Türk Efsanelerinde Taş Kesilme Motifi ve Bu Efsanelerin Tip Kataloğu. Ankara: Ankara Üniversitesi Basımevi.

Sokolov, YM. (2009). Folklor: Tarih ve Kuram. (çev. Yetke Özer). Ankara: Geleneksel Yayınları., 2009.

Şimşek, E. (2018). Kadirli (Osmaniye) ve Çevresinde Hasan Dede ile İlgili İnanış ve Menkıbeler. Orhan Kurtoğlu (ed.). IV. Uluslararası Alevilik ve Bektaşilik Sempozyumu (18-20 Ekim 2018 Ankara) Bildiriler Kitabı. 1 içinde (519-534.ss). Ankara: Hacı Bayram Veli Üniversitesi Yayınları, 2018.

Toprak, SV. (2018). Hısnımansu. Adıyaman: Adıyaman Üniversitesi Yayınları.

Türktaş, MM. (2012). Denizli Efsaneleri. (Yayımlanmamış Doktora Tezi). Pamukkale Üniversitesi Sosyal Bilimler Enstitüsü, Denizli.

Yalçınkaya, F. (2019). Anadolu Efsanelerinde Kadın ve Çocukların Kuşa Dönüşmesi Motifi. Motif Akademi Halkbilimi Dergisi, 12(28), 945-955.

Yeşildal, Ü. Y. (2018). Bir Arketip Olarak Yılan. Avrasya Uluslararası Araştırmalar Dergisi, 6(13), 420-431. 